\title{
Cell-based construction site simulation model for earthmoving operations using real-time equipment location data
}

\author{
Nipesh Pradhananga ${ }^{1}$ and Jochen Teizer ${ }^{2^{*}}$
}

\begin{abstract}
Background: Simulation is a proven technique for effective construction site layout planning and heavy equipment resource optimization. Traditional simulation uses historical data as input for task durations. Data is fed into activity cycle diagrams which many times do not consider any of the rapidly changing spatial constraints that are present on a construction site. Very little research has been conducted towards more realistic, real-time simulation involving data gathering from live actors and documenting the effect of potential changes to such a spatial-temporal work environment.
\end{abstract}

Methods: Cell-based simulation, incorporating continuous spatial changes to the site layout during project operations and real-time Global Positioning System (GPS) location tracking data from equipment resources, is introduced for more realistic and rapid modeling. The potential of analyzing and visualizing the effects of spatial consideration of varying resource combinations in earthmoving cycles on productivity and site congestion are explored. It provides insight and awareness in decision making for resource management, site layout and internal traffic control planning.

Results: The proposed cell-based simulation system handles complex and more realistic scenarios. Various cell parameters were tested in a case study of common earthmoving operations. The advantages of the cell-based over a traditional simulation model include ease of visualization and simplicity in modeling spatial constraints (e.g., ramp restricting traffic to one-way flow). The system provides full control over the flow of resources by using predefined rules or algorithms. It simplifies the design process since, except for some certain key cells, other ordinary cells followed the same rules without being programmed individually. Future research may involve multiple, non-interacting crews competing for resources and study of time-space conflicts in more detail.

Conclusions: The presented cell-based simulation system is able to model and visualize the cyclic activities of earthmoving equipment that occur on a construction site in greater detail than previous simulation methods have done. Using near real-time location data from equipment as input value in the simulation helps construction site project engineers, planners, and managers to improve coordination and monitoring of such construction resources.

Keywords: Earthmoving operation; Global positioning system; Heavy equipment resources; Modeling; Real-time location tracking; Simulation; Data visualization

\footnotetext{
* Correspondence: jochen@teizer.com

${ }^{2}$ RAPIDS Construction Safety and Technology Laboratory, Ettlingen, Germany

Full list of author information is available at the end of the article
} 


\section{Introduction}

Simulating earthmoving operations is a classic example of simulation in construction engineering and management. Although it is done primarily to optimize the productivity of cycling resources (e.g. dump trucks), it mainly assists decision making by estimating the right numbers of required resources that perform a task. The traditional way of developing a simulation model has been using Activity Cycle Diagrams (ACDs). ACDs are precedence diagrams with connected nodes representing the resources and activities (Martinez 2001). A queue of events is generated in such simulation models. The simulation is event driven and conditions are checked only when an event occurs in the queue. Such diagrams easily get complicated when the number of events increases or the numbers of conditions grow. Besides, these diagrams do not consider spatial constraints on site and large effort has to be put into the diagrams to incorporate space as a resource.

Space on many of today's construction sites is a rare commodity. As resources and activities need to be scheduled based on existing spatial constraints, construction site layout plays an important role for the success of project operation execution. Planning through simulation often involves identifying problems and opportunities of existing construction site environments ahead of time (Ning et al. 2011). Common construction site conditions, like congestion and proximity among competing trades and resources, cannot be handled if spatial constraints are not taken into account. Cell-based systems have proven to be very effective for modeling complex systems involving spatial considerations (Mitchell 2009).

This article describes a framework for developing a cell-based simulation model for cyclic earthmoving operations. There are myriads of benefits of choosing cellbased system over traditional ACDs. Firstly, cell-based systems are known for the ease in modeling complex systems. Unlike traditional simulation where the activities or resources act as entities, each cell in a cell-based system can update its state based on predefined conditions. Construction resources that occupy cells in the grid and move to adjacent cells, follow a calculated path. The cells interact with the neighbor cells and affect their state based on the neighbors. Since spatial consideration are taken into account in the presented study, location data from resources can be directly related to the cells for the input analysis. This study also presents a novel approach towards visualization of the entire simulation without any additional effort. Occupancy of cells already give the location of the resources at any given time in the simulation.

This article is organized as follows: it first synthesizes the relevant literature in the field of simulation. It then describes the methods for developing a cell-based simulation system for an earthmoving operation. The article introduces into technology for real-time location tracking, error measurements, and also outlines the parameters that need to be considered for modeling the cells and algorithms. Experiments to a field trial of the developed cellbased simulation model are presented. Results to program the truck load cycles, analyze, and visualize the output for enhanced decision making are explained. The article concludes with a discussion and future research needs.

\section{Background}

Typical construction earthmoving operations are repetitive in nature and activities are generally performed in cycles. Hence, Activity Cycle Diagram (ACD)-based simulation models are very common applications in the construction industry. Event generation mechanism in an ACD is based on activity scanning of each instance. The CYClic Operations NEtwork (CYCLONE) model, developed by Halpin (1977), focuses on the typical cyclic construction operation. State and Resource Based Simulation of Construction Processes (STROBOSCOPE), developed by Martinez (1996), represents a newer generation system for construction simulation based on ACDs. Other tools, like Hajjar and AbouRizk (1999) introduced SIMPHONY, have been developed focusing on special purpose simulation. These systems provide services that developers can use to control different system behaviors. They also provide platforms for the graphical representation of operations, animations, and statistical tools for input and output data. Templates in these systems provide a user-friendly environment, for example, the different construction operations exist as blocks for building new simulation systems. Even non-simulation experts easily comprehend the functionality of these systems. However, these systems do not consider spatial constraints or spatial interactions among resources, which can be a crucial factor in resource optimization. To resolve these shortcomings, Kamat and Martinez (2001) created a system that coupled ACD-based simulation results with $3 \mathrm{D}$ visualization for the purpose of detecting potential operational risks. Although some basic spatial reference was introduced into the simulation, the system cannot handle space-optimization problems.

Another approach of simulating a model is to build complex systems using Cellular Automata. The concept was developed by Mitchell in the 1940s (Mitchell 2009). A theory for Discrete-Event systems Specification (DEVS) was defined by Zeigler (1976) as a formal method for building models in a hierarchical and modular approach. This method is based on a cell space model consisting of an infinite set of geometrically defined cells. Each cell can have many layers corresponding to the attributes that the cell might have. The behaviors of the cells depend upon the state of neighbor cells in the system. The cell-based 
approach was further explored by Wainer (2009) for the development of Cell-DEVS. This approach considered cell spaces as discrete event models and allowed easier ways to model a complex system. A toolkit called CD++ explored this approach further and has already been implemented in many different types of applications.

Cellular Automata (CA) has been used to model and solve problems in a wide variety of science fields (Wolfram 2002). It has been applied in developing games (Nowak and May 1993), parallel computing and nanometer-scale classical computing (Benjamin and Johnson 1997), modeling physical and biological systems in nature (Toffoli 1984), social sciences (Albin 1975), and music (Burraston et al. 2004). In the context of civil engineering, CA has been successfully implemented in structure analysis and design (Missoum et al. 2005), traffic modeling and control (Gershenson and Rosenblueth 2011; Smith et al. 1995), water distribution systems (Keedwell and Khu 2006), and environmental and urban planning models (Li and Yeh 2000). The use of cell-based simulation in construction operations is relatively new. Zhang et al. (2007) implemented a cell-based modeling approach for spatially distributed resources in a construction site. They also described steps for creating a cell-based model and demonstrated a case study of a bridge re-decking process. The case study involved removing old and installing new panel sections. The feasibility of the approach was tested for construction environments by comparing the results to those obtained from MicroCYCLONE. Hammad and Zhang (2011) conducted a feasibility study using small scaled, physical equipment models for construction equipment collision detection. The study's objective was to overcome drawbacks in traditional simulation modeling that use historical, statistical data instead of real data from the site. The research also concluded that spatio-temporal representation of resources has potential to enhance safety analysis. By feeding real-time data into a simulation model, instant model adjustments can represent the real work environment.

\section{Methods}

\section{System description}

For this project, the System Under Investigation (SUI) is a construction operation involving earth moving activity. A typical earthmoving operation involves excavation, hauling dirt, and piling up the dirt at a different site. The excavation site was modeled and the activities occurring at an excavation pit were studied. The different entities involved in the SUI are described next.

\section{Study site}

The size of the construction site for an academic office and laboratory facility was approximately $120 \mathrm{~m} \times$ $100 \mathrm{~m}$. The total excavation volume had been estimated at approximately $30,500 \mathrm{~m}^{3}$ of clay earth. The excavation lasted over the winter for 5 months. The excavation process was interrupted several times because of bad weather (e.g., rain) and for other reasons. The site contained general site infrastructure, e.g., the excavation pit, temporary driveways, an entry and exit ramp into the pit once the excavation depth was deep enough, trailers for the site office, several material lay down and storage areas, and restrooms.

\section{Resources}

The construction resources present at the site were equipment, workers, materials and space. The equipment involved in the earthmoving operation was assessed and a number of "excavators" and "dump trucks" were selected as the prime focus of this simulation model. Workerson-foot were involved, but their prime duty was only to coordinate the operation. Since they were not directly involved in the operation they were not included into the simulation. The operation involves clay dirt as a material. For the simulation, an unlimited availability of dirt is assumed. Space is considered as a resource that is used by other resources and will be optimized. The number of excavators varied between one and two on a daily basis. A tracked loader with a bucket was also used to load the dump trucks. The number of available dump trucks ranged from 10 to 20 on a given day. The capacity of each truck was $9 \mathrm{~m}^{3}$. The bucket of an excavator held $1.5 \mathrm{~m}^{3}$ of dirt when the load was flush with the bucket's sides. The same loading capacity was assumed for the track loader. However, their capacity under a heaped capacity is more like $2 \mathrm{~m}^{3}$.

\section{Construction operation}

An earthmoving operation consists of four major activities, namely, "loading", "hauling", "unloading" and "returning". In this particular case, loading involves the excavator making swings to fill the bucket and pour the dirt into the truck bed to fill it. A swing involves filling the bucket with the dirt from the site and dumping it onto the truck. Hauling involves the movement of the dump truck from the point where it gets loaded by an excavator to the point where it unloads the dirt. Unloading involves the truck unloading its dirt at the dump site and returning to the excavator for the next trip, which is called "returning". Figure 1 shows three of these four activities (returning, loading and hauling) at the actual site under consideration. The unloading activity has not been considered for this study because the unloading occurred outside the observed work zone. The same excavators and trucks repeatedly performed the operations throughout the observation time.

\section{Dataset}

Global Positioning System (GPS) data loggers were attached to the excavators throughout the day. For the 


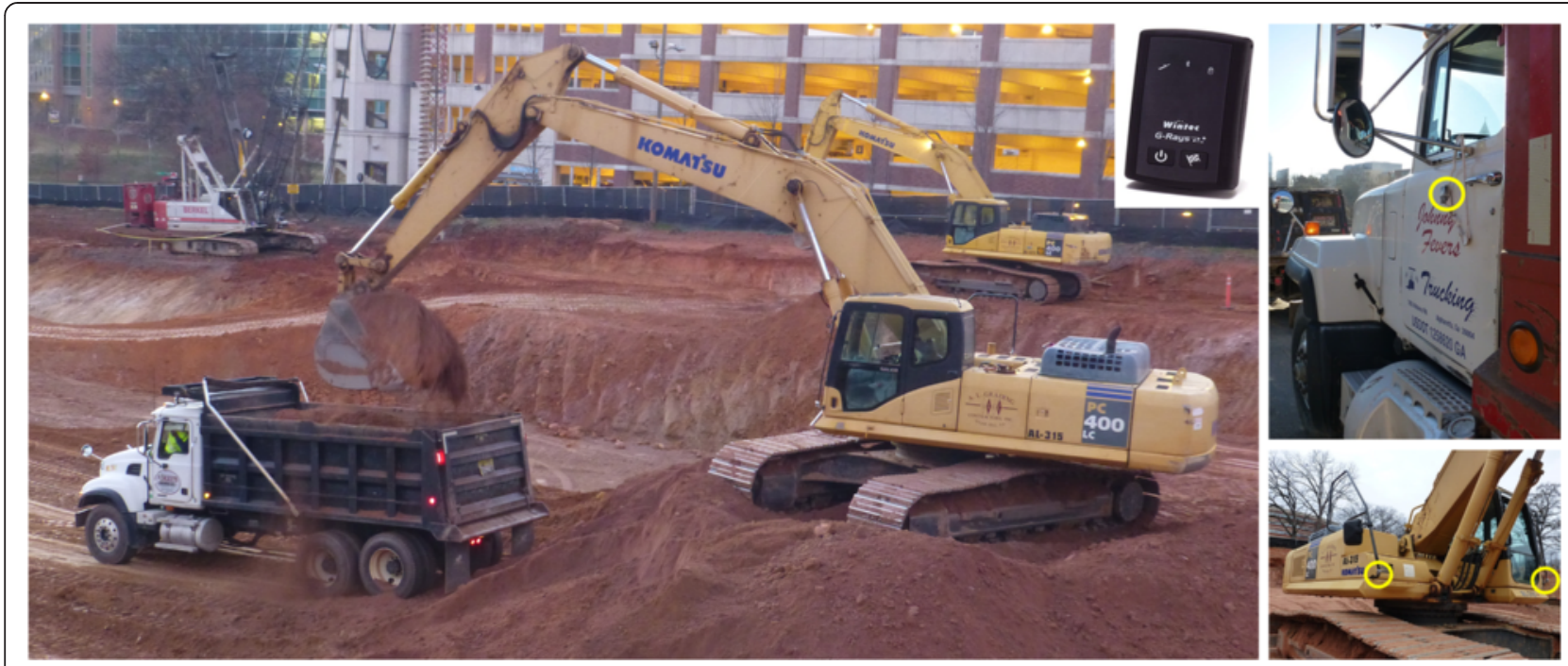

Fig. 1 Typical loading and waiting activities on a construction site with GPS data loggers mounted on the hauling and excavation equipment

trucks, one GPS data logger was attached to the trucks at the entry gate to the site and removed at the exit point. After the review of classical construction simulations, a limitation of this study is that not the entire cycle path could be observed. Due to privacy issues the dump location could not be observed. This was mainly due to the fact that the dump truck drivers were all local hires and agreement among all drives to record the entire travel cycles could not be achieved. However, data were recorded for the entire time of operation the resources (excavators and trucks) were on site. Data was eventually downloaded and stored at the end of each working day. The objective of the study was to collect real-time data using GPS data loggers, but to process it afterwards off-site. The utilized GPS technology (incl. error rate, location recording frequency, and type and amount of data) is explained in detail in Pradhananga and Teizer (2013). The mounting locations of the GPS equipment on the construction vehicles are shown in Fig. 1. A few notes: the frequency of data collection through these devices was $1 \mathrm{~Hz}$. Only the parts of the hauling and returning activities that lie inside the site were considered for the simulation. The crews (incl. equipment) started working at around 6:30 AM and stopped at around 5:30 PM. All truck and excavation equipment drivers volunteered their participation.

\section{Construction site characteristics}

Like any other production systems, the SUI also operates under cost and schedule constraints. Optimal usage of the available resources is desired to maximize productivity (i.e., time) and reduce operating costs of machinery and personnel involved. Focusing on the two main types of resources, excavators and trucks, their numbers on site depend upon the production goals of the day. Increasing the number of resources does not always result in increased production on a construction site. If there are fewer trucks than the excavators can load at a time, the excavators have to wait for the trucks to arrive. The hourly operating cost of excavators makes this equipment type ideal for optimization. If there are more trucks than the excavators' capacity can handle, the trucks would have to wait for the excavators. Choosing fewer trucks, in such a case, not only saves money but also avoids site congestion. Since fewer trucks idle and potentially congest the driveway less, other equipment is able to utilize these more efficiently. It should be noted that all the movements into, on, and outwards of a typical construction site happens through specifically designated temporary entry gates and paths, which often become a bottle neck, especially in urban construction site environments. In these cases, congestion at the site has an adverse effect on all the activities happening at that site and close to it.

Since space is a scarce resource on modern construction site, mindful positioning of equipment and crews can significantly boost productivity and safety on site. For an earthmoving operation, generally all the trucks use a ramp into and out of the excavation pit. There, they get loaded by the excavator(s). Alternative equipment, if available, is a tracked bucket loader on tracks (see Fig. 2). Additional dozer(s) typically push dirt for a short distance to increase the productivity of the aforementioned equipment. Hence, positioning the excavators (or track loaders) at optimal locations is an important factor to optimize excavation operations. If the interarrival times of the trucks are not regulated, many trucks may arrive together at once. As a result, they may leave 




Fig. 2 Resource overcrowding and undercrowding situations at an excavation site: Dump trucks queuing up in- and outside the construction site at 7:22 A.M. and leaving soon later at 7:47 A.M

the site at nearly the same time. A site can suffer from serious overcrowding and under-crowding situations throughout the day, hampering the overall site productivity. Figure 2 illustrates such examples at the observed construction site. At 7:22 AM several trucks queued up, even outside the site. A few minutes later at 7:47 AM, the excavators soon run out of trucks they can fill (see also another example of an idling excavator in Fig. 1). Because of the cyclic nature of events, these conditions are likely to persist or repeat throughout the day.

\section{Results and discussion Simulation system}

The developed simulation system consists of three interacting components (see the framework in Fig. 3): the input, the simulation engine, and the output. Real-time data, simulation engine, and optimization of resources have been studied in great detail individually. This research presents a framework that brings the system components together as a single entity and verifies it in a construction setting. Discrete Event Simulation (DES) models - commonly used in construction industry - cannot be directly used for visualization. The proposed framework binds real-time data to the continuous simulation system. It also can be used for real-time site operation monitoring. Beyond monitoring, the cell-based simulation system has potential to assist site managers to analyze and visualize the consequence of plan changes and even helps them in making informed decision by automatically suggesting the optimum resource combination. The output module is fed to the system through a feedback loop which is again used to analyze and visualize the system in real-time based on previous observations. Each part is discussed in detail in the following sections.

\section{Input analysis}

The automated construction operation analysis system described in Pradhananga and Teizer (2013) determined that 136 trucks were loaded during the observation day. The loading times were tested for multiple curves using the Arena software package. The gamma distribution was found to be the best fit. A gamma distribution with a Shape factor of 13.1621 and a Scale factor of 7.5266 were calculated. Figure 4 shows the histogram of the loading times and the gamma curve fitting the distribution. An autocorrelation check was performed for the loading times. Figure 5 shows the autocorrelation plots with one degree of lag (see Fig. 5a) and with 1 to 20 degrees of lag (see Fig. 5b). There was no significant autocorrelation found in the loading times.

One peculiar situation was observed when multiple trucks waited at the entrance gate before the site opened. Hence, the initial inter-arrival times at the start of the work day could not be considered for the analysis. A total of 125 inter-arrival times were identified and used for the input analysis. A gamma distribution with a Shape factor of 0.8377 and a Scale factor of 320.0542 was fitted to the distribution (see Fig. 6). The autocorrelation check was performed to the inter-arrival times but did not yield any significant results. Figure 7 shows the autocorrelation plots. A stationary analysis was not performed because the system was not assumed to be stationary. 


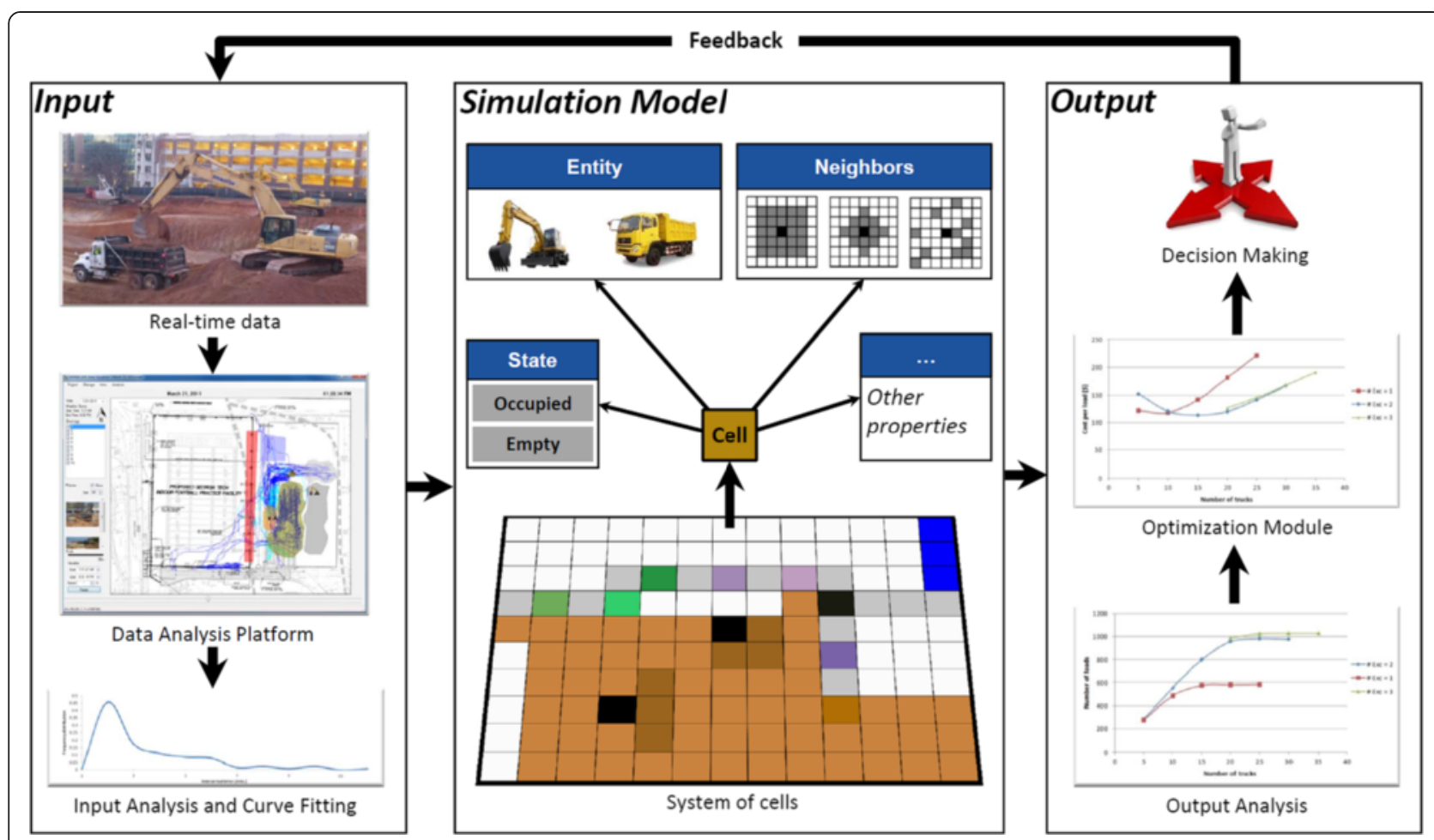

Fig. 3 Cell-based construction site simulation system

Simulation engine, objectives, assumptions, and properties There are many commercial simulation software packages available that perform complex systems simulation using cellular automata. This research requires a system that intakes real-time from the site and dynamically updates the simulation model. A cell-based simulation based on complex systems was developed from scratch in MATLAB ${ }^{\mathrm{TM}}$. The proposed system is also capable of incorporating feedback from new observations and perform the simulation in ever changing context of the site. The objectives, and assumptions that a cell needs to hold along with other system properties are explained next in the context of the selected earthmoving site.

The main objectives of the simulation are:

- To generate spatio-temporal information from a simulation model based on real-time data from a site for a different resource configuration.

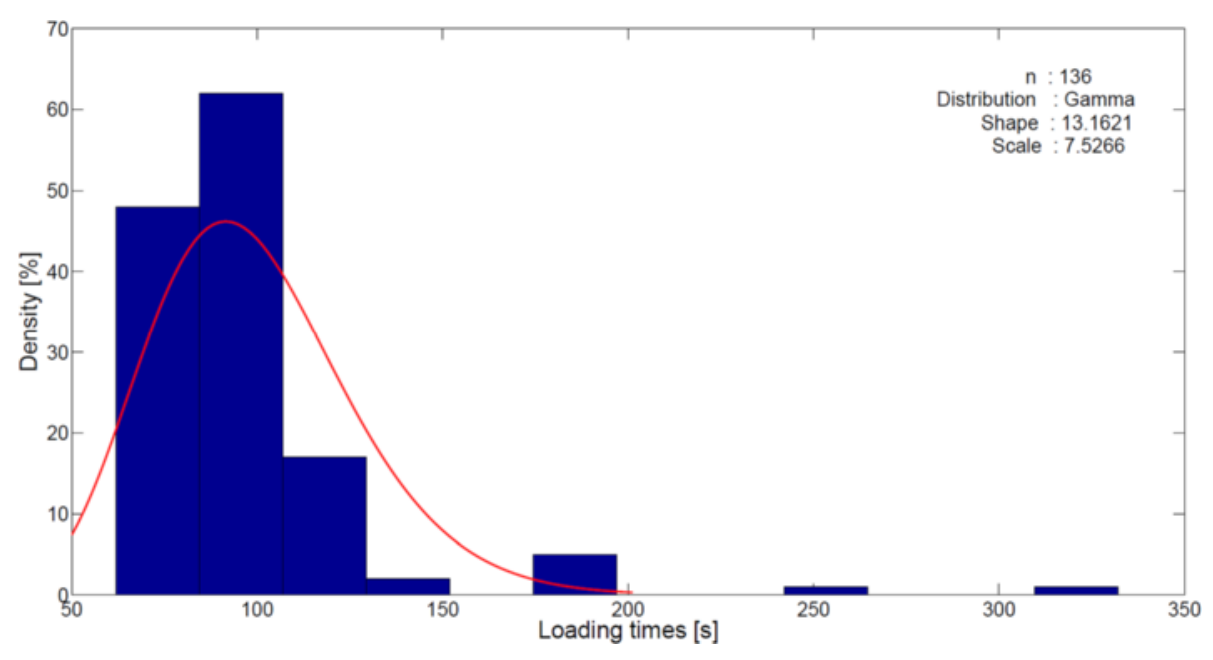

Fig. 4 Curve fitting for the loading times 


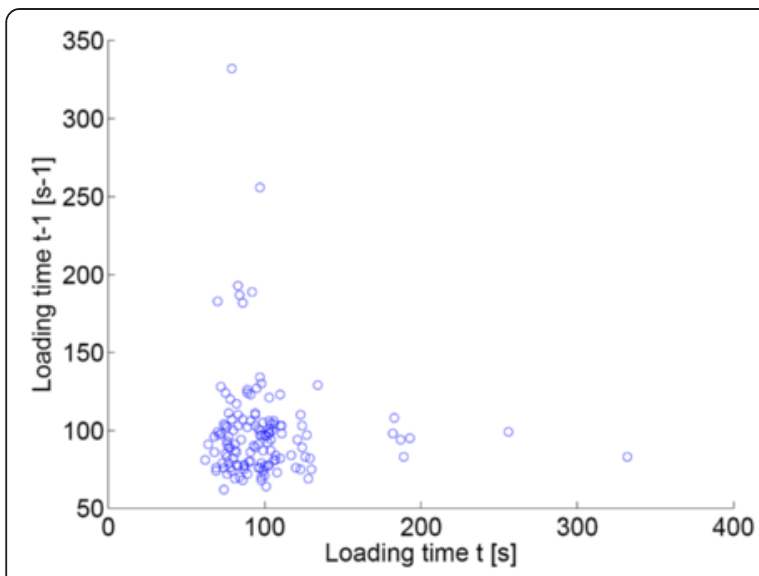

(a)

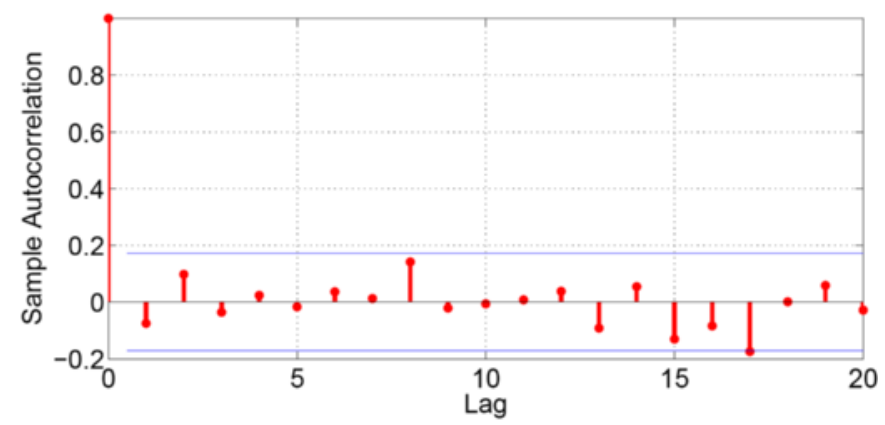

(b)

Fig. 5 Autocorrelation analysis of the loading times: (a) Autocorrelation plot and (b) Autocorrelation analysis with multiple lags

- To implement a complex systems method for simulating an earthmoving operation using a cell-based model.

- To analyze the effect of changing the number of resources (excavators, loaders, and trucks) on productivity.

- To predict the optimum number of resources (excavators, loaders, and trucks) for a given production volume for a day, using real data from the site by performing a sensitivity analysis.

The following assumptions were made for simplifying the system and construction of the simulation model.

- No other vehicles use the driveway.

- No equipment downtime or breakdown takes place.

- Trucks wait only inside the construction site and their movement is not constrained outside.
- Trucks do not enter any other part of the site that is not considered in the simulation.

- The operation is never disrupted (i.e., due to weather, site issues).

- No other activities take place in the entire site while the earthmoving is in progress.

- No activities take place beyond the cellular system outside the site.

- All equipment operators are equally skillful.

- The external traffic conditions do not affect the inter-arrival times of trucks (stationary system).

- The excavators can be placed at any point inside the pit without affecting the excavation process (this assumption requires other equipment like dozers and loaders to push earth towards the excavator while the excavator can load the trucks without moving its position throughout the day).

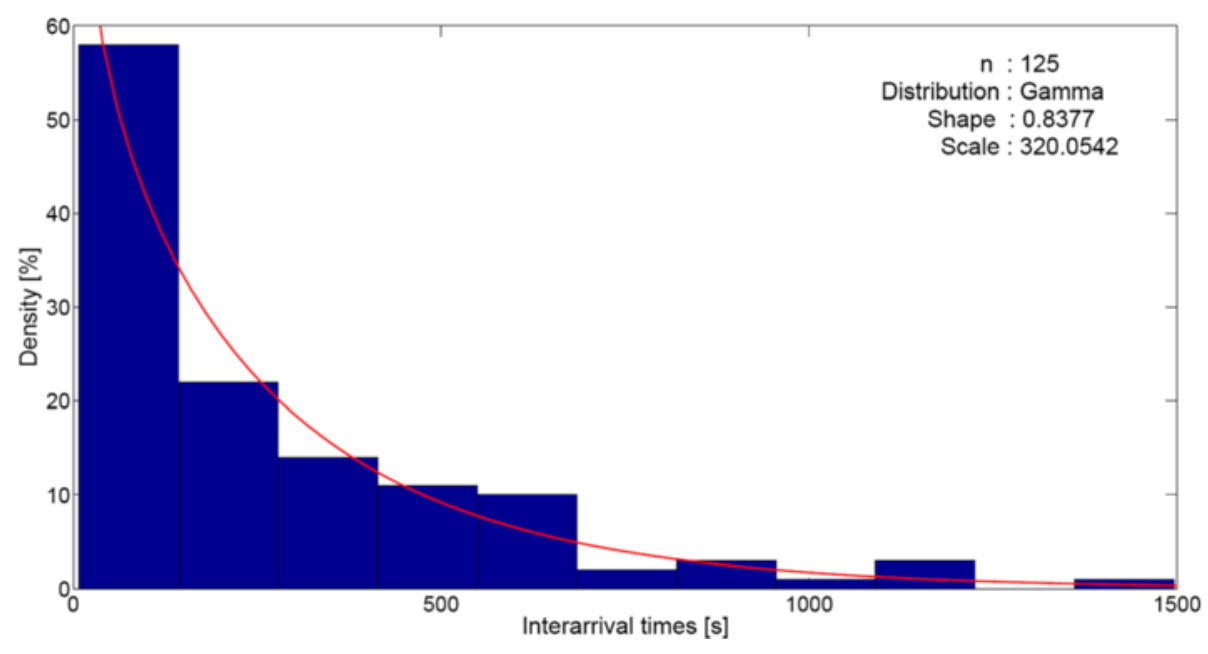

Fig. 6 Curve fitting for the inter-arrival times 


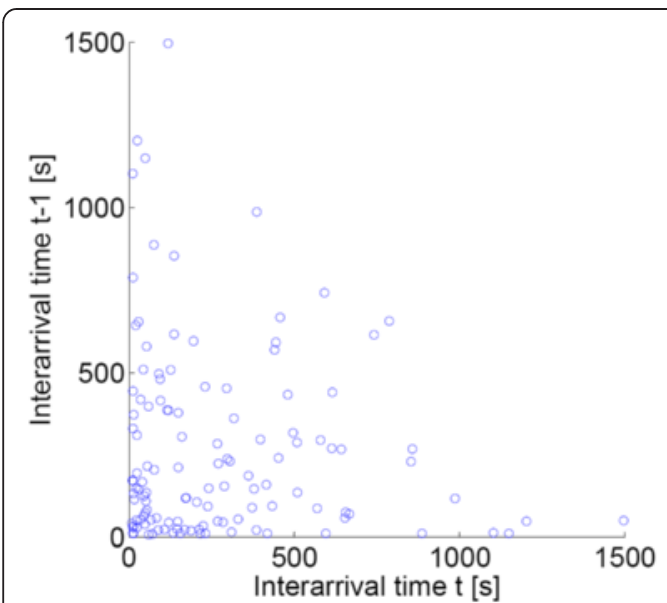

(a)

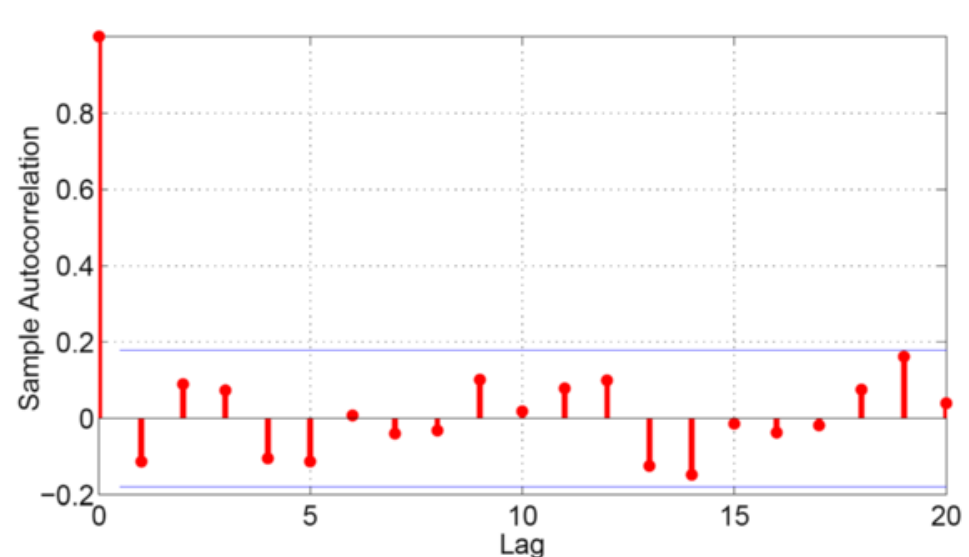

(b)

Fig. 7 Autocorrelation analysis of inter-arrival times: (a) Autocorrelation plot and (b) Autocorrelation analysis with multiple lags

- The trucks travel inside the site through a guided driveway.

- The velocity of all the trucks inside the site is uniform.

- An unlimited amount of dirt is available (if needed).

The following properties were considered:

- Lattice geometry: A two-dimensional (2D) grid was considered for the system representing the site area and ignoring the elevation difference among parts of the site. Figure 8 shows different types of the lattice geometry. The elevation difference between the driveway and the excavation pit is covered by the trucks on the ramp. This elevation difference has not been included for simplification of the simulation model because it does not alter the movement style of the resources. In cases where a three-dimensional (3D) simulation model is desired, a 3D lattice should be adopted. An example of such a case would be the erection of a multi-story building.

Figure 9 shows the selected cellular grid layout of the site. A truck was a little more than $8 \mathrm{~m}$ in length. Hence, the grid size was selected to be $9 \mathrm{~m} \times 9 \mathrm{~m}$, considering the length of the truck and the space between two consecutive trucks. A second reason for selecting this grid size was that a truck could be represented by a single cell. The average speed of the trucks on site, observed via the GPS data loggers (see Fig. 1), was roughly $3 \mathrm{~m} / \mathrm{s}$. Selecting a $9 \mathrm{~m}$ wide grid implies that a truck would take about $3 \mathrm{~s}$ to cross a grid. Consequently, the frequency of one update per every $3 \mathrm{~s}$ appropriately represented the developed system. The considered simulation was bound horizon for an 8-h work day without break.
As shown from satellite or airborne imagery (see Fig. 9a) (Siebert and Teizer 2014), the zones have been surveyed and annotated with different colors. The cells in white represent the part of the site where no excavation activity occurred. Those cells never needed to be updated. The trailer area represented the office area and did not need to be updated (see Fig. 9b). The simulation starts once a truck enters the site through cell numbered 40 (see Fig. 9c). The truck follows the driveway (in grey) to cell 36 and proceeds down the ramp to into the pit that starts with cell 101. From cell 101, the truck moves to the loading location, near or next to an excavator or track loader, and waits for being loaded with material. The inter-arrival times of the trucks and the loading times for the excavators are the two stochastic processes in this system. Once filled, the truck returns to cell 101 and then exits the pit through the ramp to cell 52, where it leaves the site through the exit gate. At the exit, an inter-arrival time is assigned to the truck along with a fixed time that it would take to travel to the dump site and return to the site, where it then enters the site again through cell 40.

An interesting consideration in the developed simulation is the function of the ramp that connects the excavation pit to the driveway on site. The ramp restricts entering and exiting the system. Only one truck could pass through the ramp at a given time. Checking only the immediate neighbor could lead to a head-on collision of the trucks on the ramp and result in a deadlock. Details on how the movement through the ramp has been handled are described in the following sections.

- Neighborhood size: Fig. 10 shows the various types of neighborhoods according to Toffoli and Margolus 1987. In this system, a von Neumann neighborhood 


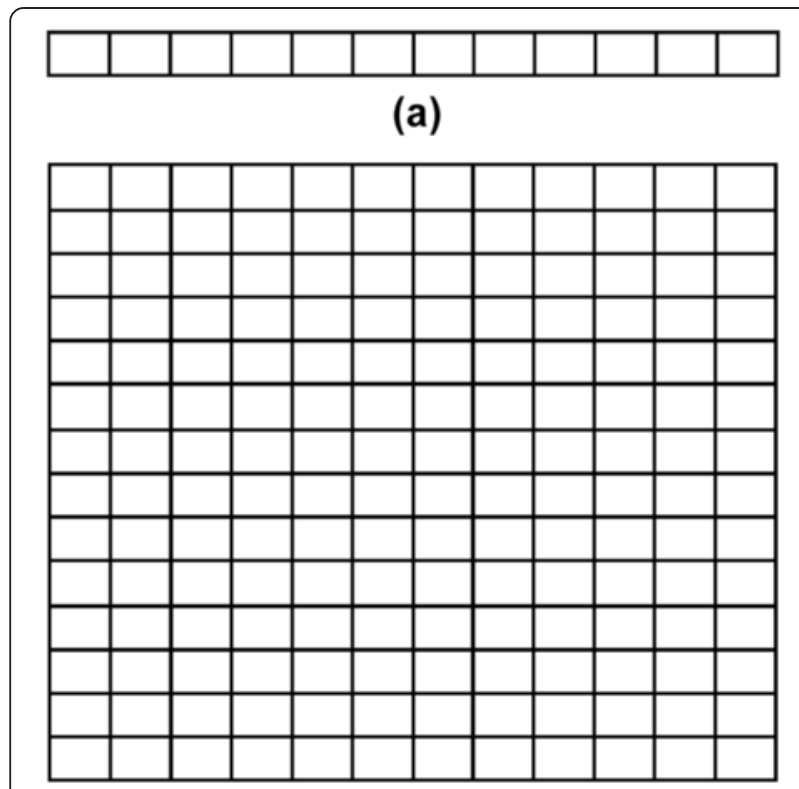

(b)

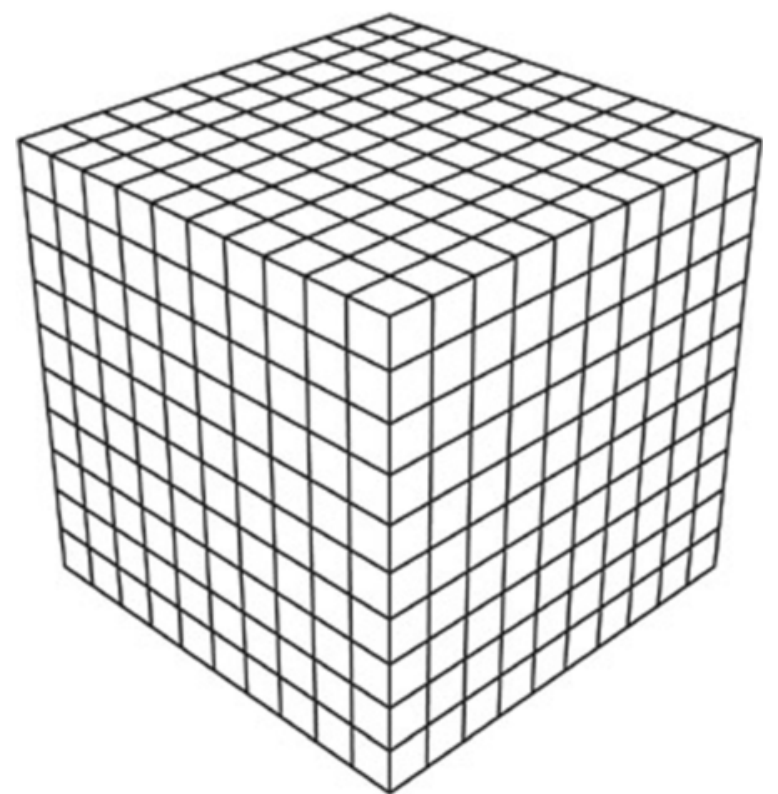

(c)

Fig. 8 Lattice geometry: (a) one-dimensional, (b) two-dimensional, and (c) three-dimensional

was assigned to the cells on the driveway to prevent trucks from passing another on the driveway (see Fig. 10a). The use of von Neumann neighborhood prevents a truck from moving diagonally. This would have restricted trucks from passing by other trucks in the event of a close proximity. A Moore neighborhood was assigned to cells in the excavation pit to allow free movement in the absence of dedicated lanes (see Fig. 10b). For exceptional cells

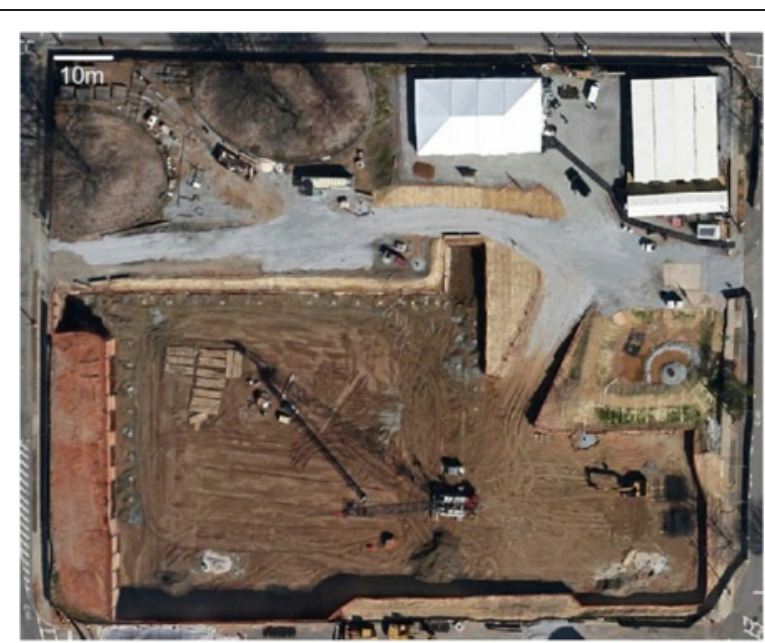

(a)

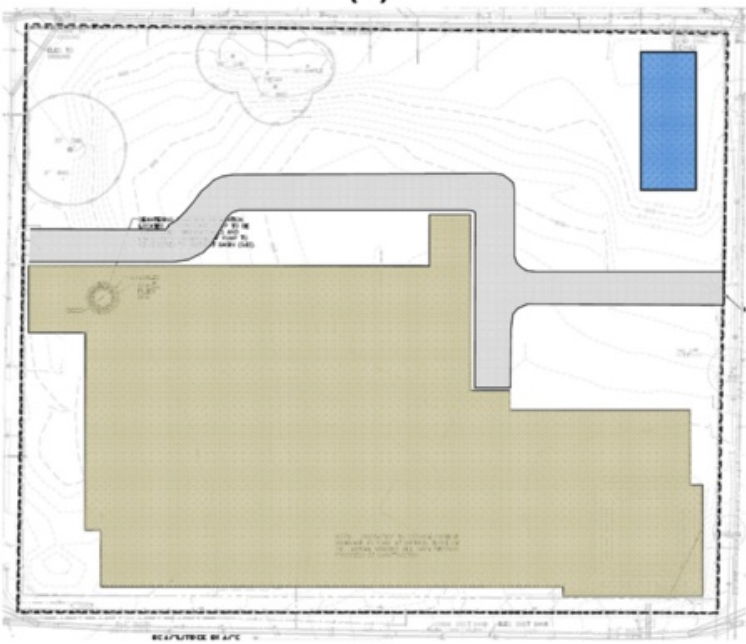

(b)

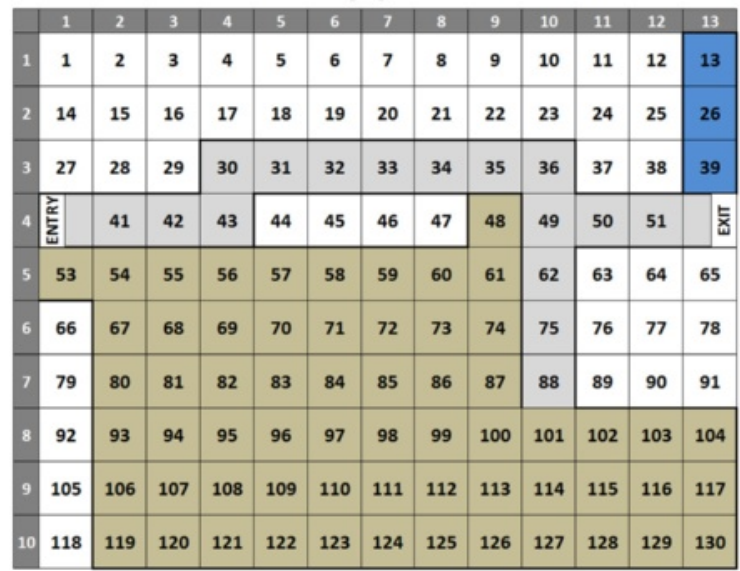

Pit area Temporary road Offices (c)

Fig. 9 Transformation of the site into a cell-based grid system: (a) Satellite or UAV image, (b) Simplified site layout map with zones, and (c) Construction site divided into cells 


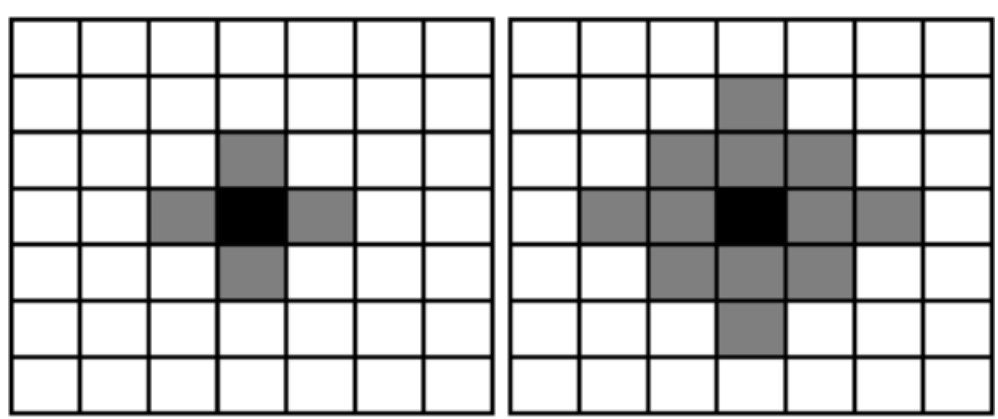

(a)
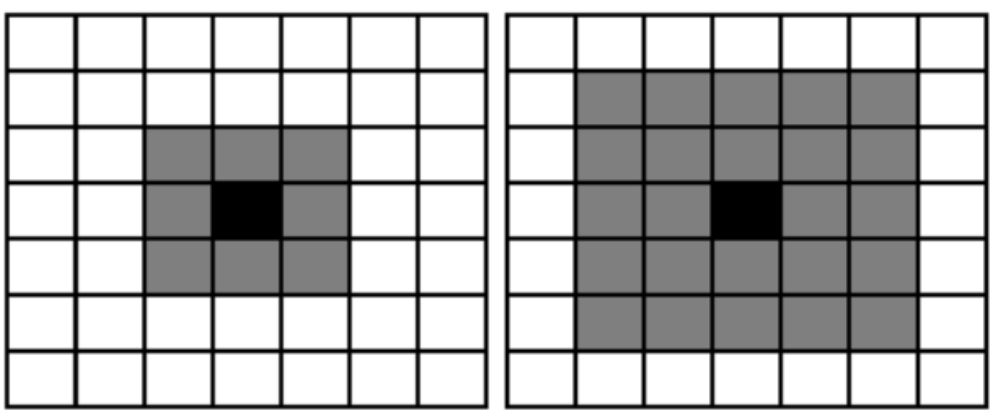

(b)

Fig. 10 Neighborhood types: (a) Von Neumann and (b) Moore

that controlled the flow of trucks from one zone to another, an arbitrary neighborhood was implemented.

- Boundary conditions: A fixed value boundary condition represented the site conditions the best (see Fig. 11c). Periodic (Fig. 11a) or reflective (Fig. 11b) boundaries extend the boundary beyond the site which was not desired.

- State set: The state of a cell was labeled 0 if it was unoccupied and 1 or 2 if it was occupied by a truck or an excavator at a given time, respectively.

- Initial conditions: The information about the zones in which the cells lie was provided through a comma separated values (CSV) file. The zones included 0 for cells not considered for any activity, 1 for the driveway, 2 for the excavation pit, 3 for the loading area of the excavator, and 4 for the trailer.

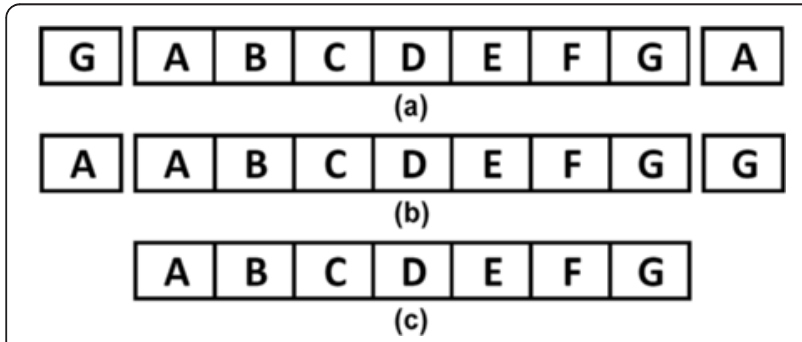

Fig. 11 Boundary conditions: (a) Periodic, (b) Reflective, and (c) Fixed value
Similarly, the positions of the excavator and corresponding loading area were also fed into the system through a CSV file during initialization.

- Transition rules: Instead of direct specification or probabilistic rules, a multi-step transition rule-based system was adopted. This means that different ranges of cells would compute different parameters before making the next move. The algorithm followed the transition rules shown in Fig. 12.

The algorithm loops through all the neighbors of the cell under consideration. Each cell is assigned to a target cell to which the movement is directed. For each neighbor of that cell, an occupancy test is performed to assess if the cell is willing to welcome any occupant. If the cell is available, a zone test is performed on the cell to confirm that the movement would be constrained to the same zone. Now, the cells passing both these tests are compared for the distance to the target cell. A movement occurs only if moving to that cell reduces the distance towards the target.

Figure 13 shows the trajectory that a truck follows in the system. Cells 36 and 101 are controlling cells and are governed by special transition rules. Following are descriptions of what happens to key cells in the system:

Cell 40: Truck enters the system. Cell 36 is assigned as the target cell.

Cell 36: This cell checks if any loading area (cell) is available around any of the available excavators in the pit. If yes, it will check if any loaded truck is still in the 

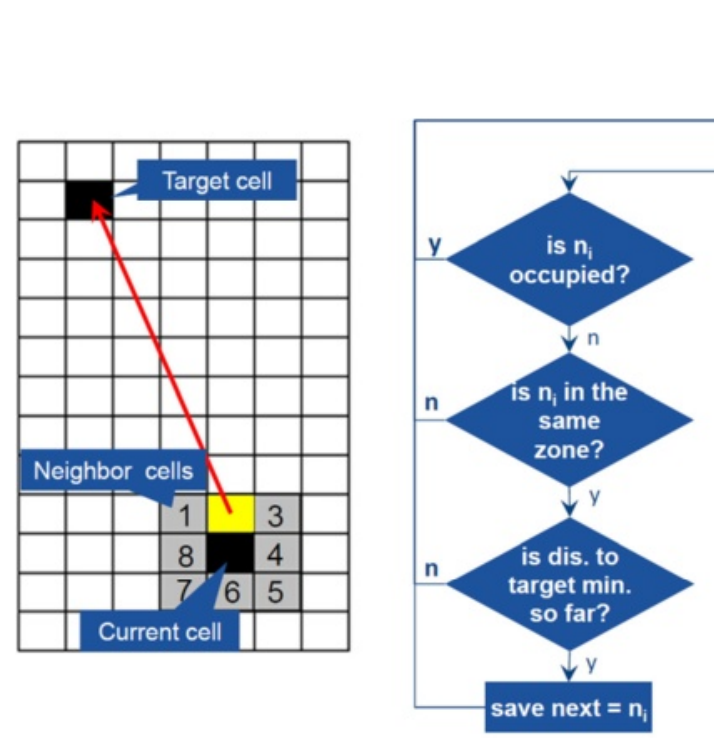

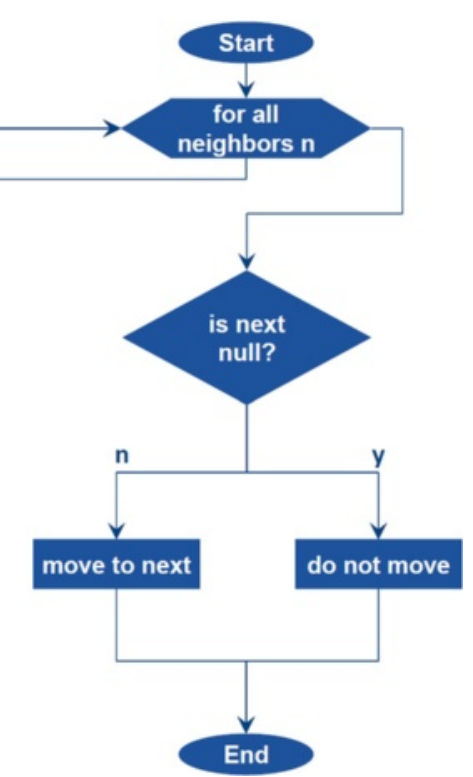

Fig. 12 Algorithm defining the transition rules

pit. If a loading truck is in it, it might block the ramp within a reasonable, short amount of time. If no loaded trucks are inside the pit, cell 36 still checks if any loaded trucks are already on the ramp (from cells 36 to 101). If none of the above-mentioned conditions are present, it will set the truck's target to cell 101 and also assign a loading zone to the truck. The loading zone next to an excavator having the least number of trucks next to it, is assigned to the truck.

Cell 101: This cell is the bottleneck in the earthmoving operation. This cell has to be passed by both unloaded and loaded trucks. For this reason, before any truck enters this cell, a test first makes certain that no cells are currently on the ramp in the opposite direction (entering or leaving the pit). The truck may, however, follow another truck moving in the same direction on the ramp. Cell 101 also exhibits a different rule for loaded and unloaded trucks. If an unloaded truck comes to this cell, it will redirect it to the loading zone next to the excavator which has been assigned to that truck. If a loaded truck comes to the cell, the cell will forward it to cell 52, which is the site exit. Cell 101 is also the only cell in the system where a truck changes zones (i.e., from driveway zone to pit and back).

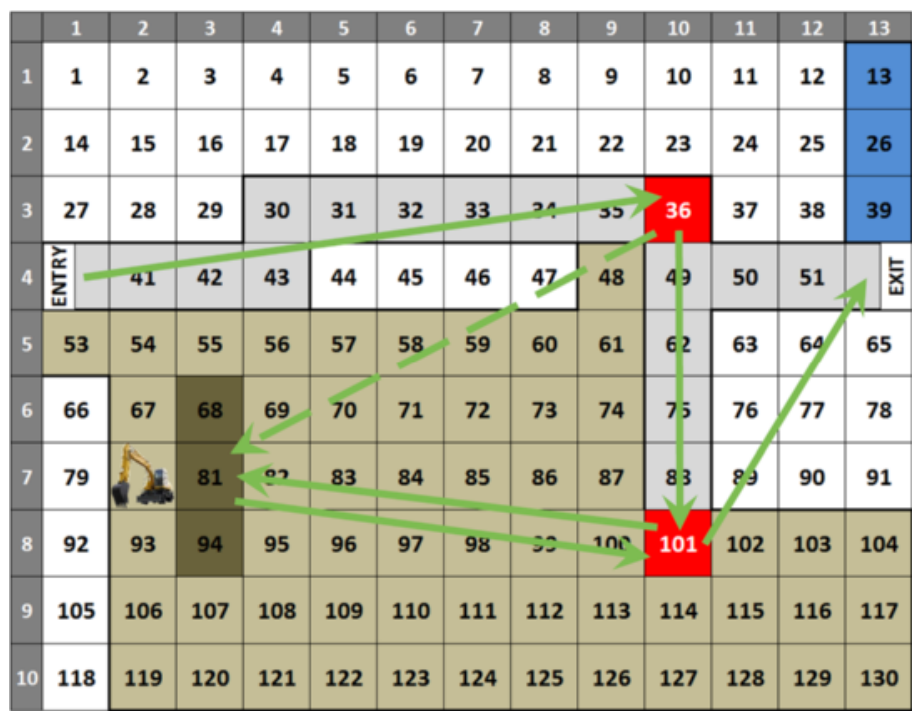

Excavation pit

Driveway

Office trailer

Key cell

Loading zones

Excavator

Fig. 13 Grid system with transit points 


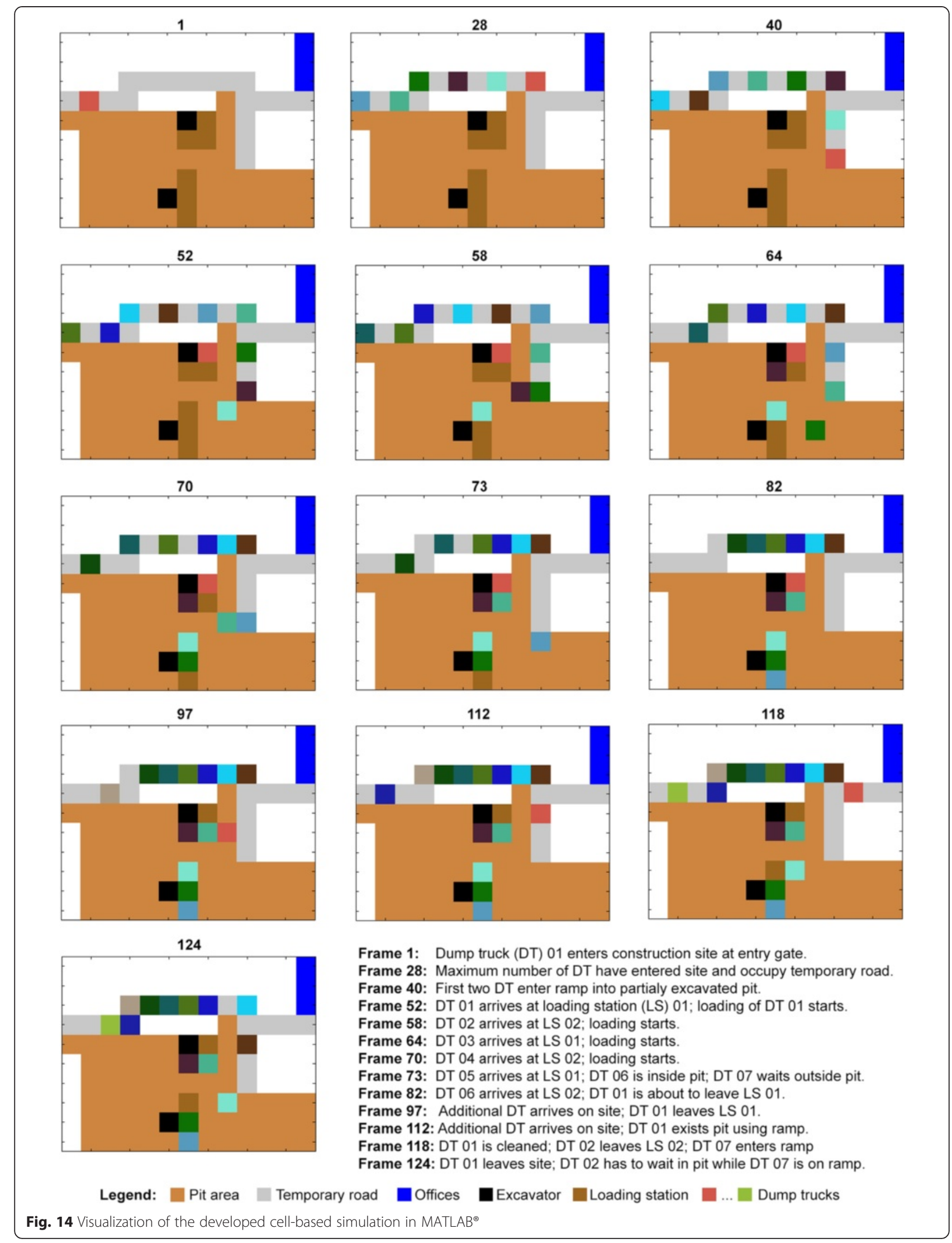


Cell 52: This is the exit cell. It assigns the next arrival time for the truck and moves the truck out of the system. The trucks arrive at the entry cell (40) based on the inter-arrival time assigned here.

\section{Output analysis}

The first advantage of implementing a cell-based system is that it can visualize the site and resource movements directly without any further processing. Figure 14 visualizes one instance. The locations of the trucks in all instances can be recorded and used for spatio-temporal analysis, as done in early research work by Pradhananga and Teizer (2014) and Vasenev et al. (2014).

Like traditional simulation models, cell-based models are also capable of performing sensitivity analysis for varying number of resources on the site. Figure 15 shows the results of simulating the system for up to two excavators and multiple trucks. Each point in the chart represents the result of 50 runs in the simulation. The curve flattens at a point and remains stagnant. This is because the maximum production capacity of the excavators is reached when there are more trucks on the site than can be loaded. Any addition to the number of trucks will not yield additional production.

It can be observed in Fig. 15 that for less number of trucks, the number of trucks govern the total production. That means, irrespective of the number of excavators, the total production will not increase because the trucks are already delivering their maximum potential. In this scenario, there is a chance that the excavator has to wait for new trucks to arrive at the site. As the number of trucks increases again, the excavators are busy and trucks have to wait to get loaded. In terms of production, it would be beneficial to have more excavators on site. Figure 15 depicts this scenario. For this SUI, the tipping point occurs at around 50 trucks. The total production for one or two excavators is the same if the number of trucks is less than 50. After one excavator's capacity is reached, we only see a surge in production if we deploy more excavators (two in this case).
Figure 15 also shows a case when both the excavators work at their maximum capacity (with roughly 100 trucks serving the site). Sending more trucks to the site will not yield any further increase in production. An extension to Fig. 15 would be the total production with three excavators on site. It can be expected that the production steadily increases beyond the capacity 100 trucks can carry, but becomes stagnant at a higher number of trucks.

Resource optimization is a classic problem that simulation models are used for. Identifying the maximum productivity can be utilized to optimize the cost of the operation. For instance, it can help to determine the number of excavators and trucks that yield the most production for the same cost per load. Conversely, if a production level needs to be accomplished, the optimal resource configuration that yields the production level for the lowest cost can also be computed (see Fig. 16).

The major benefit from implementing a cell-based simulation model is that it uses a continuous simulation model and simulates the position of all the resources at each instance. This is not possible in a discrete-event simulation model. Discrete-event simulation triggers only when an event occurs. Since the focus of this research was to analyze the interaction of the resources at each instance, cell-based simulation has to be implemented to thoroughly understand the interaction even when no notable event occurs.

\section{Feedback and model verification}

The valuable information obtained by simulating the site under different site conditions is applied in future operations through a feedback loop. New decisions are implemented and real-time data are continuously collected. These further enhance the simulation system and provide better decision making capacity.

Model verification is the process of confirming that the right model has been built for the system. In the case of a cell-based system, the entire simulation process can be observed in the visualization environment. Checking

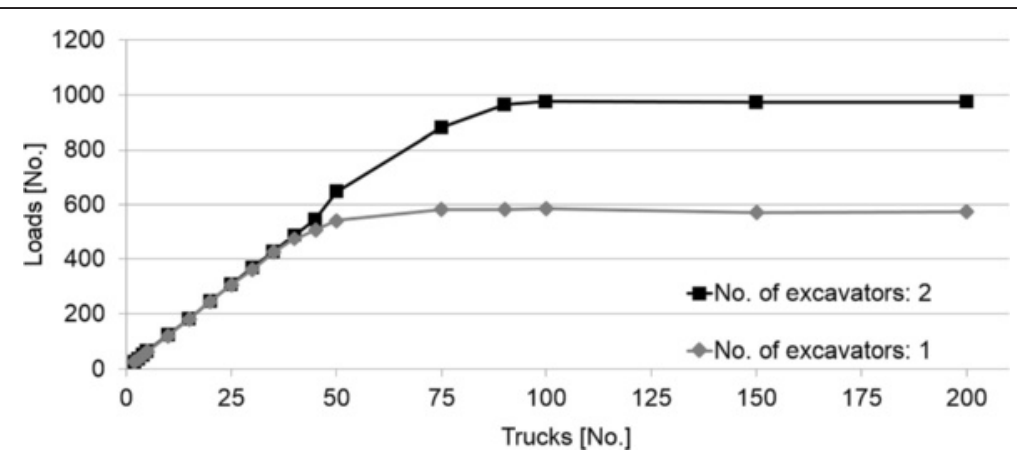

Fig. 15 Simulation output for multiple resource configurations 


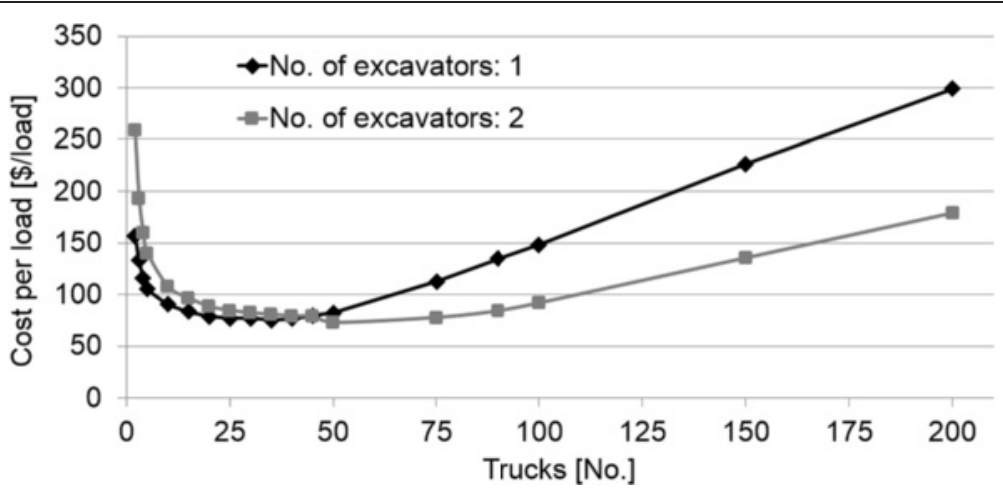

Fig. 16 Cost optimization using sensitivity analysis

the model can be done by observing the movement of the entities in the simulation system. In the selected case, the dump trucks are supposed to arrive at the entrance gate, find their way through the temporary construction road on site, wait for the ramp to be empty, wait for an empty spot next to an excavator, wait to be loaded, and then exit through the exit gate. All these activities can be visually verified to check if the model has been built correctly.

Another, more scientific way to verify the developed system is to compare the output against the output of another established simulation system. In this case, the

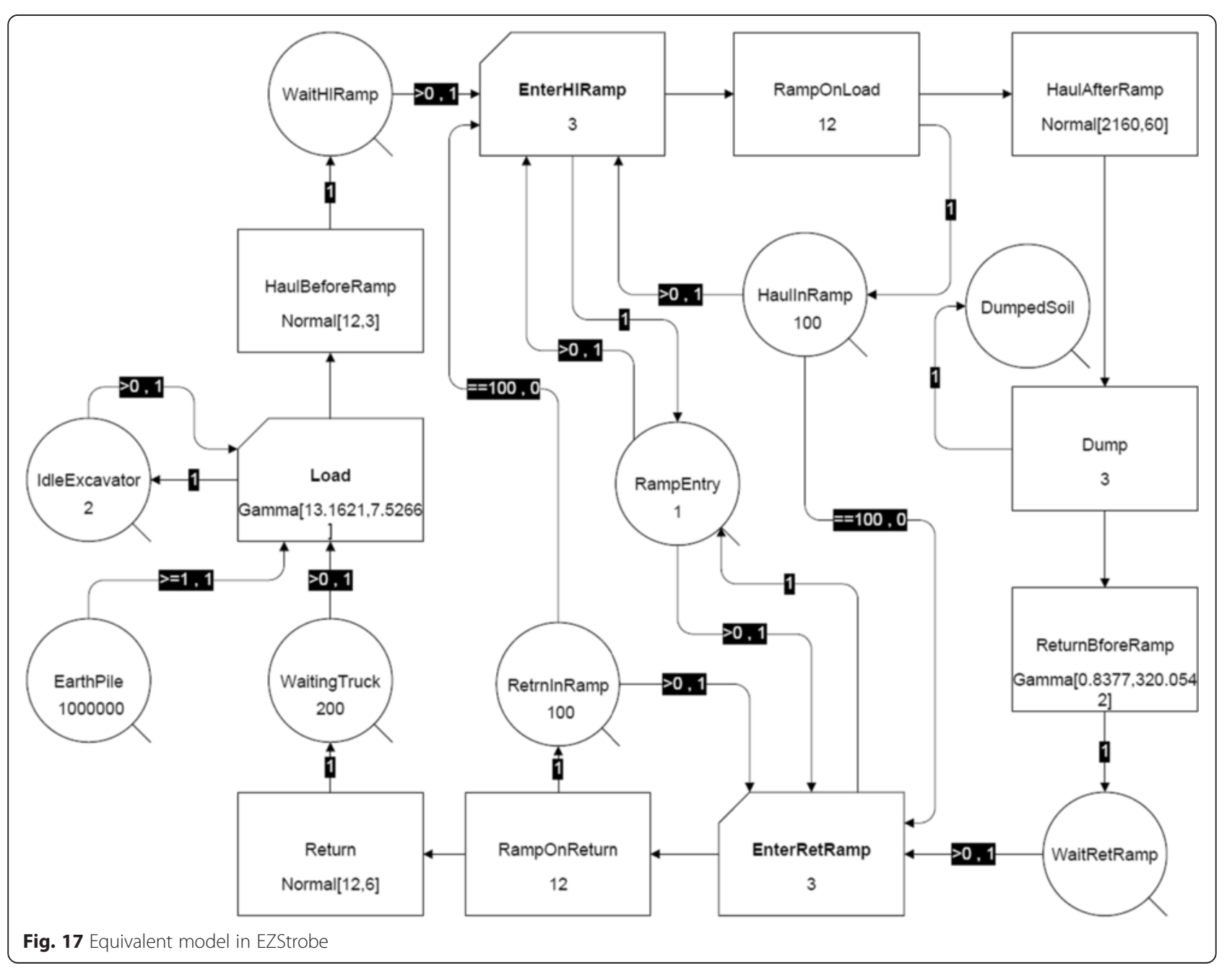


developed model is verified aganist EZStrobe (Martinez 2001). Although both models are based on completely different methodologies, their output should match if they both simulate the same site and resources. An equivalent model was built in EZStrobe. Figure 17 shows an equivalent discrete-event simulation model for the same system. Since only two stochastic processes were used in the cell-based model, the results of the two models are not expected to exactly coincide. In the cellbased system, the entities traverse through their neighbor cells and hence activities like returning and hauling times are handled by the system itself. In the model shown in Fig. 17, the nearest possible distribution was assigned to those activities based on manual judgment.

Figure 18 shows the results of the verification step. Both models are comparable in the beginning, but the predicted output from the cell-based simulation model was much larger than the predicted output by the EZStrobe simulation model. It was noticed that this deviation occurred near the saturation point for the system, where the curve starts to flatten. This discrepancy can be attributed to the assumptions made for the construction of the cell-based model. One of the major assumptions is that all the activities happen within the site (note: in the assigned cells). When the number of trucks becomes unrealistically high, some trucks (need to) line up outside of the site boundaries. The maximum number of vehicles that hauled material at the selected site was between 15 to 20 trucks, based on observations made on different days. When 50 trucks are assigned to perform the same task, the site becomes congested and subsequently insufficient to provide waiting areas for the trucks. Another difference between the two models is the existence of a ramp into/out of the excavated pit. The cell-based system allows trucks to follow one another on the ramp as long as the traffic is in one direction. The discrete-event simulation limited the mobility of the trucks on the ramp as soon as one truck is on it. This accounts for 12 to $15 \mathrm{~s}$ delays in a truck's hauling cycle time on the site. It might not make a significant difference for a small number of loads but can affect the system extensively when the excavator is working at its maximum capacity.

\section{Conclusions}

A cell-based simulation system was developed to model cyclic earthmoving activities that occur on a construction site. A method of developing the cell-based simulation model was described. The capabilities of the system to handle a complex system were demonstrated and the parameters of the cells were tested in a case study of common earthmoving operations. The advantages of using a cell-based system over a traditional simulation model include ease of visualization and simplicity in modeling spatial constraints (e.g., a ramp restricting the traffic flow to one-way). The system of cells provided full control over the flow of resources by using predefined rules or algorithms. The cell-based system also simplified the design process since, except for some certain key cells, other ordinary cells followed the same rules and did not need to be programmed individually.

Implementing real-time data into the simulation and using the feedback loop helped in creating a more realistic model. Future development of this system should include multiple crews competing for resources. Of particular interest would be studying a crew that does not interact with each other but shares the same workspace. In terms of safety applications, the developed system may provide the advantages of continuous simulation over traditional event-based simulation methods, especially when studying interaction among resources (Teizer et al. 2015). Continuous simulation generates spatio-temporal data for resources for each instance, which can be analyzed as if it had been collected from a real construction site. For such cases, workspace conflicts and the effect of one crew on work site productivity, due to congestion or other project risks, could be analyzed. The developed system could assist decision makers in regards to advancing resource

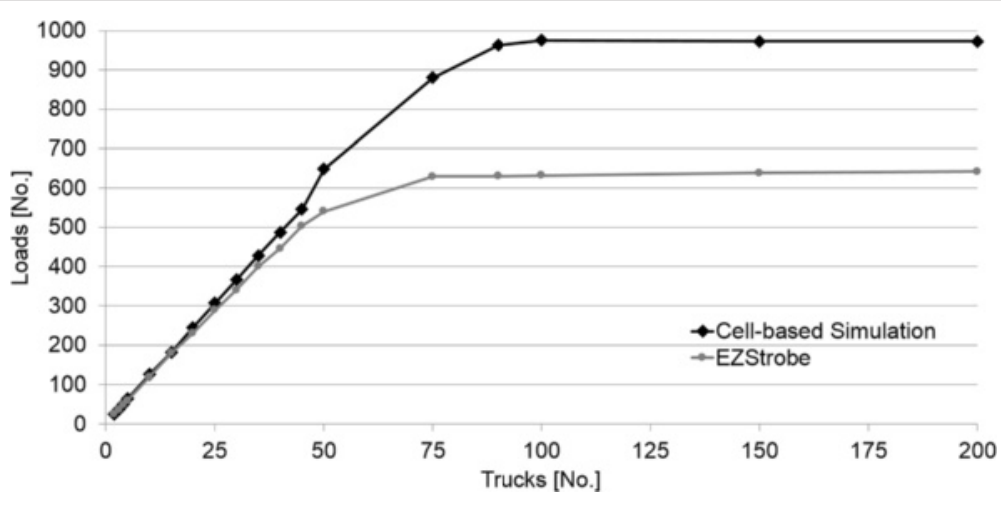

Fig. 18 Cross validation with EZStrobe 
allocation and site layout planning. It could also be used as a training tool to allow project managers to become familiar with the effects of changing resource quantity levels on site.

\section{Competing interests}

The authors declare that they have no competing interests.

\section{Authors' contributions}

Both authors contributed extensively to the work presented in this paper. NP reviewed and analyzed the literature, developed the simulation model, conducted the case study, analyzed the results, and drafted the manuscript. $\mathrm{JT}$ coordinated and supervised the entire research process of this study and edited the manuscript. Both authors read and approved the final manuscript.

\section{Author details}

${ }^{1} \mathrm{OHL}$ School of Construction, College of Engineering and Computing, Florida State University, 10555 West Flagler Street, Miami, FL 33174, USA. ${ }^{2}$ RAPIDS Construction Safety and Technology Laboratory, Ettlingen, Germany.

\section{Received: 17 February 2015 Accepted: 29 May 2015}

Published online: 04 June 2015

\section{References}

Albin, PS. (1975). The analysis of complex socioeconomic systems. Massachusetts, USA: Lexington Books.

Benjamin, SC, \& Johnson, NF. (1997). A possible nanometer-scale computing device based on an adding cellular automaton. Applied Physics Letters, 70(17), 2321-2323.

Burraston, D, Edmonds, E, Livingstone, D, \& Miranda, ER. (2004). Cellular automata in midi based computer music. In Proceedings of the International Computer Music Conference (pp. 71-78).

Gershenson, C, \& Rosenblueth, DA. (2011). Modeling self-organizing traffic lights with elementary cellular automata. Complex Systems, 19(4), 30-322.

Hajjar, D, \& AbouRizk, S. (1999). Simphony: An environment for building special purpose construction simulation tools. In Proceedings of the 31st Conference on Winter Simulation (Vol. 2, pp. 998-1006).

Halpin, DW. (1977). Cyclone-method for modeling job site processes. ASCE Journal of the Construction Division, 103(3), 489-499.

Hammad, A, \& Zhang, C. (2011). Towards real-time simulation of construction activities considering spatio-temporal resolution requirements for improving safety and productivity. In IEEE Proceedings of the Winter Simulation Conference (WSC) (pp. 3533-3544)

Kamat, VR, \& Martinez, JC. (2001). Visualizing simulated construction operations in 3D. Journal of Computing in Civil Engineering, 15(4), 329-337.

Keedwell, E, \& Khu, ST. (2006). Novel cellular automata approach to optimal water distribution network design. Journal of Computing in Civil Engineering, 20(1), 49-56.

Li, X, \& Yeh, AGO. (2000). Modelling sustainable urban development by the integration of constrained cellular automata and GIS. International Journal of Geographical Information Science, 14(2), 131-152

Martinez, JC. (1996). STROBOSCOPE: State and resource based simulation of construction processes. University of Michigan: Dissertation.

Martinez, JC. (2001). Ezstrobe: General-purpose simulation system based on activity cycle diagrams, IEEE Proceedings of the. In 33nd Conference on Winter Simulation (pp. 1556-1564).

Missoum, S, Gurdal, Z, \& Setoodeh, S. (2005). Study of a new local update scheme for cellular automata in structural design. Structural and Multidisciplinary Optimization, 29(2), 103-112.

Mitchell, M. (2009). Complexity: A guided tour. USA: Oxford University Press.

Ning, X, Lam, KC, \& Lam, MCK. (2011). A decision-making system for construction site layout planning. Automation in Construction, 20(4), 459-473.

Nowak, MA, \& May, RM. (1993). The spatial dilemmas of evolution. International Journal of Bifurcation and Chaos, 3(1), 35-78.

Pradhananga, N, \& Teizer, J. (2013). Automatic spatio-temporal analysis of construction site equipment operations using GPS data. Automation in Construction, 29, 107-122.

Pradhananga, N, \& Teizer, J. (2014). Congestion Analysis for Construction Site Layout Planning using Real-time Data and Cell-based Simulation Model (pp. 681-688). Orlando, Florida: Proceedings of the ICCCBE Conference.
Siebert, S, \& Teizer, J. (2014). Mobile 3D Mapping for Surveying Earthwork Projects using an Unmanned Aerial Vehicle (UAV) System. Automation in Construction, 41, 1-14.

Smith, L, Beckman, R, Anson, D, Nagel, K, \& Williams, M. (1995). TRANSIMS: Transportation analysis and simulation system. Seattle, WA: Proceedings of the Fifth National Conference on Transportation Planning Methods Applications. April 17-21, LA-UR 95-1664.

Teizer, J, Golovina, O, Wang, D, \& Pradhananga, N. (2015). Automated Collection, Identification, Localization, and Analysis of Worker-Related Proximity Hazard Events in Heavy Construction Equipment Operation. Oulu, Finland: Proceedings of the 32nd International Symposium on Automation and Robotics in Construction.

Toffoli, T. (1984). Cellular automata as an alternative to rather than an approximation of differential equations in modeling physics. Physica D: Nonlinear Phenomena, 10(1), 117-127.

Toffoli, T \& Margolus, N (1987). Cellular Automata Machines: A New Environment for Modeling, MIT Press, ISBN: 9780262200608, p. 60.

Vasenev, A, Pradhananga, N, Bijleveld, F, lonita, D, Hartmann, T, Teizer, J, \& Dorée, A. (2014). Information fusion approach to increase the quality of GNSS data sets in construction equipment operations. Advanced Engineering Informatics, 28, 297-310.

Wainer, GA. (2009). Discrete-event modeling and simulation: a practitioner's approach, CRC Press LLC, ISBN 9781420053364.

Wolfram, S. (2002). A new kind of science, Wolfram Media, $1^{\text {st }}$ edition, ISBN 1-57955-008-8.

Zeigler, B. (1976). Theory of modelling and simulation. New York: John Wiley.

Zhang, C, Hammad, A, Zayed, TM, Wainer, G, \& Pang, H. (2007). Cell-based representation and analysis of spatial resources in construction simulation. Automation in construction, 16(4), 436-448.

\section{Submit your manuscript to a SpringerOpen ${ }^{\odot}$ journal and benefit from:}

- Convenient online submission

Rigorous peer review

- Immediate publication on acceptance

- Open access: articles freely available online

- High visibility within the field

- Retaining the copyright to your article

Submit your next manuscript at $>$ springeropen.com 